JOURNAL OF URBAN ECONOMICS 5, 241-262 (1978)

\title{
The Long-Run Effects of a Residential Property Tax and Local Public Services
}

\author{
A. Mitchell Polinsky \\ Department of Economics, Harvard University, Cambridge, Massachusetts 02138
}

AND

Daniel L. Rubinfeld ${ }^{1}$

Department of Economics and Institute of Public Policy Studies, The University of Michigan, Ann Arbor, Michigan 48109

Received August 1, 1976; revised November 15, 1976

The long-run effects of a residential property tax and local public services are analyzed in the context of an urban spatial model. An endogenous labor market allows the local wage rate to adjust, in conjunction with residential and business land prices, in response to local fiscal changes.

\section{INTRODUCTION AND SUMMARY}

This paper analyzes separately the long-run impact of a residential property tax and the long-run impact of local public services in the context of a spatial model of an urban area with a single jurisdiction. Although this is not a balanced-budget analysis, we believe that an understanding of the separate tax and expenditure effects on urban economic structure provides useful insights. Unlike most studies of either the property tax or local public services, we allow both the price of land (residential and business) and the local wage rate to respond simultaneously to local fiscal changes. In the remainder of this section we will discuss previous studies concerned with these issues, the relationship of our analysis to these studies, and our principal assumptions and conclusions.

${ }^{1}$ This research was sponsored by the Urban Institute under National Science Foundation Grant GS-30184. Helpful comments were received from many individuals, especially Henry J. Aaron, Harvey Brazer, Robert Dorfman, John F. Kain, Herbert Mohring, Wallace E. Ouless, and Sidney G. Winler. 
Despite numerous papers on the residential property tax, there still remains substantial disagreement over the issue of tax shifting. For example, Netzer [10] stresses the view that the property tax is shifted forward to consumers in the form of higher housing prices, while Rolph and Break [16] emphasize that property taxes may be shifted backward onto all factors of production which are imperfectly mobile. The disparity of conclusions is due largely to different formal structures as well as different definitions of the commodity to be taxed. For example, Mieszkowski [9] and Orr [13] analyze the property tax solely as a tax on capital improvements, while Grieson [5], Simon [18], and Barr [2] include land as wcll as structures in their definitions of taxable property. Whereas Orr [13] and Simon [18] use models which focus on the effects of property tax changes on the prices of land and housing, Mieszkowski [9] and Barr [2] allow for changes in the prices of other factors of production such as labor and capital. ${ }^{2}$

Although there has been less theoretical work on the impact of public services, substantial disagreement exists there too. On the one hand Lind [8] and Strotz [20] have argued that an improvement in benefits will be partially capitalized in higher land and housing prices. This is also the implicit view held by Kain and Quigley [6], Oates [12], and Ridker and Henning [15] in their empirical work. On the other hand Nordhaus and Tohin [11] and Tolley [21] have argued that the local wage rate will fall in response to an improvement in amenities in a single city. As in the property tax literature, these apparently conflicting views result from different underlying models. For example, in the theoretical models of Lind [8] and Strotz [20] it is implicitly assumed that the wage rate is fixed, while in that of Nordhaus and Tobin [11] it is implicitly assumed that property values are fixed.

The approach taken in our paper may be characterized by the following points. First, our framework is a formally explicit model in which all results are obtained without assuming particular functional forms for any relationship. Second, we view the residential property tax as a tax on the value of both land and capital used in the production of housing services. Third, we analyze (separately) the effects of changes in a residential property tax and public services in a single city which is "small" in relation to a larger system of cities. Fourth, our model has an explicit spatial character to it, recognizing that urban land is not perfectly homogeneous because of differential accessibility advantages. Fifth, we allow for the fact that fiscal changes may alter decisions about business versus residential, and city versus rural land

${ }_{2}$ The works cited above are meant as examples only. See Mieszkowski [9] for the historical development of these issues, and see Aaron [1, pp. 18-55] for a survey of recent views on the "state of the art" and additional references. 
use. Sixth, our model includes an explicit business sector in which land is a factor of production. And last, our model is long-run in the sense that labor and capital are perfectly mobile within and among cities.

Section 2 of the paper describes our framework. There are three types of land use-a central business district (CBD), a surrounding residential ring, and an outer rural area. A private consumption good is produced in the CBD from land, labor, and capital, and sold locally as well as nationally. Housing services are produced at each site in the residential area from land and capital. Both capital and labor are perfectly mobile ${ }^{3}$ and each city is "small," so that the (net-of-tax) price of capital and the level of utility are equalized over space and are exogenous to each city. Each individual works in the CBD and allocates his budget among the private consumption good, housing services, property taxes, and journey-to-work costs. He also consumes local public services, the level of which depends only upon his location in the residential ring.

Sections 3 and 4 describe the independent effects on the city's equilibrium of changes in the property tax rate and public service levels, respectively. When the tax rate is increased and public services are held fixed, the wage rate and the gross-of-tax prices of housing services and capital rise and the net-of-tax prices of housing services and land fall. In addition, the city decreases in area and per capita housing consumption declines. Changes in total population and the total stock of capital (business plus residential) are indeterminate. When public scrvices are inercased and the tax rate is held constant, we expect that the price of land will rise and the wage rate will fall. In this case the net-of-tax (and gross-of-tax) price of housing services and the price of business land will rise. Also, the city will increase in area, while changes in the per capita consumption of housing services, the total population and the total stock of capital are indeterminate. However, without simplifying the model or choosing particular functional forms for the utility and production functions, other outcomes are possible. For example, the price of residential land and the wage rate may both fall as a result of public service improvements. ${ }^{4}$

${ }^{3}$ In our framework the term "capital" should be viewed as the generic name for all perfectly mobile inputs to the production process other than labor. Thus, the use of the term here is quite different from its usage in most short-run housing models.

- While our focus is on the impact of local public sector variables on factor and product prices in a single city, it is important to keep in mind the distinction between real burdens and nominal price changes. For example, it would be incorrect in our model to conclude that an increase in the tax rate (holding public services fixed) makes individuals in the city worse off then similar individuals elsewhere because it raises the (gross-of-tax) price of housing. A simulluneous increase in the wage rate will leave individuals in the city neither better nor worse off than before. Furthermore, 
Section 5 concludes with a brief discussion of the analytical difficulties involved in attempting to analyze the tax and expenditure sides simultaneously.

\section{THE MODEL}

The starting point of our analysis is the traditional theory of residential location, amended to include a property tax and a simple characterization of public services. We begin with a city which is circular and is built on a featureless plain. The central portion of the city is occupied by the CBD and the remainder is reserved for residential housing. The residential sector is surrounded by a rural area in which the price of land, denoted by $r_{2}$, is constant over space. ${ }^{5}$ For convenience we assume that land and capital are rented from an absentee landlord who does not enter the model explicitly. ${ }^{6}$ We present the remainder of the model formally in terms of four separate sectors (consumer, producer, housing, public) and the equilibrium conditions that link them together. ${ }^{7}$

\section{A. The Consumer Sector}

Assumption 1: Every individual has the same utility function and "owns" the same number of units of labor services per unit time.

Assumption 2: Every individual works a fixed number of labor units per unit time in the $C B D$, to which he makes a fixed number of trips per unit time.

It follows that each individual will also have the same ineome, although this income will be determined endogenously in the labor market. ${ }^{8}$

the real burdens and benefits of local fiscal changes may extend throughout the system of cities. See Courant and Rubinfeld [4].

"We generally use the subscripts " 0 ," " 1 ," and "2" to denote variables associated with the business, residential and rural sectors, respectively. The only exception is with respect to partial derivatives of the indirect utility function $V$; see (2.3).

${ }^{6}$ This permits us to concentrate on the impact of the property tax and public services without considering the effects of capital gains and losses associated with fiscal changes.

${ }^{7}$ Although models of the type presented below are well known in urban location theory, it is necessary to present a fully articulated model in order to make our later analysis self-contained and to make explicit our assumptions and method of introducing local fiscal variables.

${ }^{8}$ We have been unable to obtain results with a more general version of our model in which individuals differ with respect to tastes and/or income. However, in simpler urban location models, others have had limited success in introducing some of these complexities. For example, see Solow [19]. We have also been unable to obtain results 
For convenience we normalize labor units so that each individual supplies one unit of labor per unit of time.

Assumption 3: Journey-to-work costs increase monotonically with distance from the center of the city (and are independent of the wage rate). For simplicity, we are assuming that travel occurs instantaneously and that everyone travels to and from the center of the city and then receives "free transit" within the CBD. Along with Assumption \& this eliminates the need to consider leisure explicitly in the utility function.

Given the above assumptions, the individual's objective can be expressed formally as:

$$
\begin{aligned}
& \underset{c, h, x}{\operatorname{Maximize}} U(c, h, b(x)) \\
& \text { subject to } w=c+(1+t) p(x) h+j_{1}(x)
\end{aligned}
$$

where

$x=$ distance from the center of the city

$c=$ composite private good per unit time (used as the numeraire with a price set at unity)

$h=$ housing services per unit time

$b(x)=$ public services per unit time (see subsection $D$ )

$w==$ wage per unit time

$t=$ property tax rate (see subsection $D$ )

$p(x)=\left(\right.$ net-of-tax) price per unit of housing services per unit time ${ }^{9}$

$j_{1}(x)=$ journey-to-work costs per unit time

Rather than work with this (direct) utility function, we will express the household's utility, $V$, as a function of prices at a particular location, income net of transportation costs from that location, and public services at that location ${ }^{10}$ :

$$
V(x)=\tilde{V}\left((1+t) p(x), w-j_{1}(x), b(x)\right) .
$$

In terms of the indirect utility function the demand for housing can

when population density is an argument in the utility function. The resulting external effect (each individual's consumption of housing affects the utility of his neighbors) greatly complicates the analysis.

${ }^{9}$ It should be noted that the price of housing as used here is a rental price rather than a sales price (capitalized value).

${ }^{10}$ The usefulness of the indirect utility function for analyzing residential location models was first illustrated by Solow [19]. To derive the indirect utility function from the utility function, we solve for the market demand functions from the standard constrained maximization problem (with fixed income and prices), and then substitute the demand function for the commodity arguments in the utility function. In (2.2), $\tilde{V}$ is decreasing in the first argument, and increasing in the second and third. 
be expressed as minus the partial derivative of $\tilde{V}$ with respect to the price of housing, divided by the partial with respect to income:

$$
h(x)=-\frac{\tilde{V}_{1}\left((1+t) p(x), w-j_{1}(x), b(x)\right)}{\tilde{V}_{2}\left((1+t) p(x), w-j_{1}(x), b(x)\right)}=-\frac{V_{1}(x)}{V_{2}(x)},
$$

where the subscripts to $V$ and $\tilde{V}$ denote partial derivatives with respect to the relevant arguments. ${ }^{11}$

\section{B. The Producer Sector}

Assumption 4: The composite private good $c$ is produced in the $C B D$ from land, labor and capital using a constant returns to scale technology with variable factor proportions. ${ }^{12}$ The assumption of constant returns to scale allows us to express the cost per unit of output solely in terms of the factor prices:

$$
p_{c}(x)=\tilde{p}_{c}\left(r_{0}(x), w, s\right),
$$

where $p_{c}(x)=$ cost per unit of the composite private good

$r_{0}(x)=$ price per unit of land per unit time in the CBD

$s=$ price per unit of capital per unit time

and $w$ is defined in (2.1). Using (2.1) we can express the factor demands as $::^{13}$

$$
\frac{\partial \tilde{p}_{c}\left(r_{0}(x), w, s\right)}{\partial r_{0}(x)}=\text { demand for land per unit of output, }
$$

${ }^{11}$ This formula may be explained intuitively as follows: $-\tilde{V}_{1}=$ marginal utility gained with $\$ 1$ fall in the price of housing $\simeq$ (number of units of housing services consumed) ( (marginal utility of a dollar) $=$ (number of units of housing services consumed) $\cdot \tilde{V}_{2}$. Rearranging terms gives: (number of units of housing services consumed) $=-\tilde{V}_{1} / \tilde{V}_{2}$. To preserve consistent notation we will use the expression following the second equal sign of (2.3) to refer to the demand for housing.

12 This assumption is restrictive since the presence of scale economies in production is considered to be a primary reason for the existence of cities. However, one reason is still present, although hidden, in a transport assumption of our model (Assumption 5 below), which essentially limits the development of cities to regions centering on a fixed number of transshipment points. This is sufficient to generate scale cconomies in the transportation of the composite private good, rather than in its internal production process. Moreover, because of the added complexity, we will not consider taxing land and capital in the CBD and treating public services as an intermediate product in the production of the private good.

${ }_{13}$ The cost of one unit of output is equal to the demand for each factor (per unit of output) multiplied by its price and summed over all factors. Differentiating the cost function with respect to a given factor price gives the respective factor demand plus some terms whose sum can be shown to be zero. 
$\frac{\partial \tilde{p}_{c}\left(r_{0}(x), w, s\right)}{\partial w}=$ demand for labor per unit of output,

$$
\frac{\partial \tilde{p}_{c}\left(r_{0}(x), w, s\right)}{\partial s}=\text { demand for capital per unit of output. }
$$

Assumption 5: The composite private good $c$ is sold in a national market from the center of the city, and transportation costs to the center per unit of output, denoted $j_{0}(x)$, increase monotonically within the CBD. ${ }^{14}$ The cost at the center of the city of one unit of the private composite good produced at distance $x$ is therefore $p_{c}(x)+j_{0}(x)$.

\section{The Housing Sector}

Assumption 6: Housing services $h$ are produced from land and capital using a constant returns to scale technology with variable factor proportions. ${ }^{15}$ Given this assumption we can also express the cost per unit of housing services solely in terms of the factor prices:

$$
p(x)=\tilde{p}\left(r_{1}(x), s\right),
$$

where $r_{1}(x)$ is the price per unit of land per unit time in the residential sector, $p(x)$ is defined in (2.1) and $s$ is defined in (2.4). Using (2.8) we can express the factor demands as:

$$
\begin{aligned}
& \frac{\partial \tilde{p}\left(r_{1}(x), s\right)}{\partial r_{1}(x)}=\text { demand for land per unit of housing services, } \\
& \frac{\partial \tilde{p}\left(r_{1}(x), s\right)}{\partial s}=\text { demand for capital per unit of housing services. }
\end{aligned}
$$

\section{The Public Sector}

Since we are concerned with the effect of a given tax rate and public service schedule on factor and output prices, we will treat the public sector as exogenous (in the sense that individuals take as given the tax rate and service schedule).

Assumption 7: There is an ad valorem tax, denoted $t$, on the prices of land and capital used in the production of housing services. Because the

${ }^{14}$ In Assumption 9 below we assume that $e$ is perfectly mobile among cities and interpret this to mean that the cost of transporting $c$ from the center of the city to any residential location (in any city) is zero.

${ }_{15}$ We have chosen to let public services enter the utility function directly rather than to treat them as an intermediate product in the production of housing services. See Assumption 8 below. 
cost function (2.8) is homogeneous of degree one, an equal ad valorem tax on the price of each factor is equivalent to the same ad valorem tax on the net price of housing services, i.e.,

$$
\tilde{p}\left((1+t) r_{1}(x),(1+t) s\right)=(1+t) \tilde{p}\left(r_{1}(x), s\right)=(1+t) p(x) .
$$

Note that the factor demands per unit of output (2.9) and (2.10) are unaffected by changes in the property tax ceteris paribus, since the factor price ratio remains unchanged.

Assumption 8: The composite local public service $b(x)$ is provided unequally over space (in general) and enters positively into individual utility functions. At each distance the public service is like a pure public good in that consumption is nonexcludable and independent of the population at that distance.

\section{E. Equilibrium Conditions and Accounting Identities}

Assumption 9: The city is "open" in the sense that labor, capital and the private consumption good are perfectly mobile within and among cities. In equilibrium, this assumption implies that the level of utility, the price of capital $s$, and the price of the private consumption good " 1 ," will be equal over spuce.

Assumption 10: The city is "small" in the sense that it is one of a large number of open cities. Given this assumption, we can treat the common level of utility, the common price of capital and the common private good price as exogenous to any one city (even though they are determined endogenously in the general equilibrium of the system of cities).

Assumption 11: All markets are perfectly competitive and in long-run equilibrium. This assumption, along with Assumptions \& and 6 , implies that prices are equal to average (and marginal) costs.

Locational equilibrium (2.12). ${ }^{16}$ By Assumptions 9 and 10 the pattern of housing prices must be such that each individual achieves the exogenous common level of utility, $V^{*}$, regardless of his location. This relationship implicitly determines the equilibrium land price schedule. In general the slope of the land and housing price schedules may be positive or negative, depending on the relationship between journeyto-work costs and public service variations over space. ${ }^{17}$

${ }^{16}$ Equations (2.12) through (2.21) are contained in Table 1.

17 This may be seen by differentiating (2.12) with respect to $x$ and then solving for $r_{1}^{\prime}(x)$, the slope of the land price schedule. The land price schedule will decline as long as a small movement away from the CBD results in a grealer ulility loss fron higher transportation expenses than it does in a gain from improved public services. 
TABLE 1

Summary of the Model

$(2.12)$

\section{Locational equilibrium}

Land market equilibrium

$$
\begin{gathered}
\text { Product market } \\
\text { equilibrium }
\end{gathered}
$$

Labor market equilibrium

Total population (labor supply)

$$
\begin{aligned}
& \text { Business-residential } \\
& \text { boundary condition }
\end{aligned}
$$

$$
V^{*}=\tilde{V}\left(\tilde{p}\left((1+t) r_{1}(x),(1+t) s\right), w-j_{1}(x), b(x)\right)
$$

$$
\left(-\frac{V_{1}(x)}{V_{2}(x)}\right) \frac{\partial \tilde{p}\left(r_{1}(x), s\right)}{\partial r_{1}(x)} n(x) d x=2 \pi x d x
$$

$$
1=\tilde{p}_{c}\left(r_{0}(x), w, s\right)+j_{0}(x)
$$

$$
2 \pi \int_{0}^{x_{0}} \frac{\partial \tilde{p}_{c}\left(r_{0}(x), w, s\right) / \partial w}{\partial \tilde{p}_{c}\left(r_{0}(x), w, s\right) / \partial r_{0}(x)} x d x=N
$$

$$
N=\int_{x_{0}}^{x_{1}} n(x) d x
$$

$$
r_{0}\left(x_{0}\right)=r_{1}\left(x_{0}\right)
$$

$$
\begin{aligned}
& \text { City-rural } \\
& \text { boundary condition }
\end{aligned}
$$

$$
r_{1}\left(x_{1}\right)=r_{2}
$$

Total tax revenue

$$
T^{\prime}=t \int_{x_{0}}^{x_{1}}\left(-\frac{V_{1}(x)}{V_{2}(x)}\right) \tilde{p}\left(r_{1}(x), s\right) n(x) d x
$$

Total business capital

$$
K_{0}=2 \pi \int_{0}^{x_{0}} \frac{\partial \tilde{p}_{c}\left(r_{0}(x), w, s\right) / \partial s}{\partial \tilde{p}_{c}\left(r_{0}(x), w, s\right) / \partial r_{0}(x)} x d x
$$

Total residential capital

$$
K_{1}=\int_{x_{0}}^{x_{1}}\left(-\frac{V_{1}(x)}{V_{2}(x)}\right) \frac{\partial \tilde{p}\left(r_{1}(x), s\right)}{\partial s} n(x) d x
$$

Land market equilibrium (2.13). The total supply of residential land in any given annulus $(x+d x)$ is approximately $2 \pi x d x$. The total demand for land in the annulus is equal to the demand for housing per person (2.3) times the demand for land per unit of housing services (2.9) times population "density," denoted by $n(x) .{ }^{18}$ Equating the demand and supply for residential land gives (2.13) ${ }^{19}$

18 Residential population "density," $n(x)$, refers (as we use it) to the number of individuals in the annulus $(x+d x)$. The more common definition of population density - the number of individuals per unit of land area, that is $n(x) / 2 \pi x$-would complicate the notation. Nothing of substance is affected by the choice of definition.

${ }^{19}$ It is unnecessary to include an equation associated with land market equilibrium in the business sector because all of the private good produced can be absorbed in the national market. Output of the private good, and consequently the derived demand for land, will adjust by construction to equilibrate the land market. 
Product market equilibrium (2.14). Since the private consumption good is the numeraire with a price equal to unity, (2.14) follows from (2.4) and Assumption 5. Demand is always equal to supply in this market at the exogenous price. Condition (2.14) determines the implicit relationship between the price of land in the business sector $r_{0}(x)$ and the wage rate $w$.

Total population (labor supply) (2.16). Total population, denoted $N$, is defined by (2.16), where $x_{0}$ is the boundary between the business and residential sectors and $x_{1}$ is the boundary between the eity and the rural area. Since we are measuring labor in units corresponding to one individual's labor supply per unit time, we can refer to total population and labor supply interchangeably.

Labor market equilibrium (2.15). Dividing the demand for labor per unit of output (2.6) by the demand for land per unit of output (2.5) gives the demand for labor per unit of land. Multiplying this by the amount of land at each location in the business sector and summing over all locations gives the total demand for labor. Setting demand equal to supply yields (2.15).

Total tax revenue (2.19). Total property tax revenue is equal to the $\operatorname{tax}$ rate times the tax base. The tax base is equal to the demand for housing services per person (2.3) times the net price per unit of housing (2.8) times residential density, summed over all locations.

Business-residential boundary condition (2.17). At the boundary between the business sector and the residential sector, the bids of business users of land will equal the bids of residential users of land. If this were not true, then it would pay one of the users to outbid the other just on the other side of the boundary, driving up land prices on the lower side and depressing them on the higher side until equality is achieved. ${ }^{20}$

City-rural boundary condition (2.18). At the boundary between the city and the surrounding rural area the bid price of residential users will equal that of rural users, assumed to be constant over space. ${ }^{21}$

Total business capital (2.20). First divide the demand for capital per unit of output in the business sector $(2.7)$ by the demand for land per unit of output (2.5) to get the demand for capital per unit of land.

${ }^{20}$ In order for the business sector to be located in the interior of the city, it is necessary to assume that the business land price schedule is steeper than the residential land price sehedule at the boundary. This in turn imposes certain restrictions on the transportation cost schedules, $j_{0}(x)$ and $j_{1}(x)$.

${ }^{21}$ At the boundary the residential land price gradient must be declining, for otherwise residential users could increase their utility by just outbidding rural users at a slightly greater distance from the CBD. In addition, we implicitly assume that the boundary of the city is unique. 
Multiplying this by the supply of land at each location and summing over all locations gives $(2.20)$.

Total residential capital (2.21). Total residential capital is equal to the demand for housing per capita at each location (2.3) times the demand for capital per unit of housing (2.10) times residential population density, summed over all locations.

This completes the description of the model. The unknowns are business and residential land prices, $r_{0}(x)$ and $r_{1}(x)$, the wage rate, $w$, total tax revenue, $T$, residential population density, $n(x)$, total population, $N$, the business-residential boundary, $x_{0}$, the urban-rural boundary, $x_{1}$, total business capital $K_{0}$, and total residential capilal, $K_{1}$. From these variables we can also solve endogenously for the demand for housing $\left(-V_{1}(x) / V_{2}(x)\right)$ and the net price of housing $\left(\tilde{p}\left(r_{1}(x), s\right)\right)$. The exogenous variables in the system are the level of utility, $V^{*}$, the price of capital, $s$, the price of the private consumption good, 1 , the property tax rate, $t$, the rural price of land, $r_{2}$, the business transportation cost schedule, $j_{0}(x)$, the journey-to-work cost schedule, $j_{1}(x)$, and the public service schedule, $b(x)$. Note that of the ten equations three are accounting identities $[(2.19),(2.20)$, and (2.21)] and two are boundary conditions $[(2.17)$ and (2.18)]. The remaining five equations $[(2.12)-(2.16)]$ are the primary relationships which are used in deriving the results of sections 3 and 4 . We will assume that a unique and stable solution exists.

\section{THE EFFECTS OF A RESIDENTIAL PROPERTY TAX}

,In this section we examine the effects of an increase in the residential property tax rate when public services are fixed. ${ }^{22} \mathrm{We}$ will prove by contradiction that an increase in the property tax rate $t$ lowers land prices everywhere in the residential sector (Theorem 1) and raises the wage rate (Theorem 2). Following these proofs we will discuss the comparative static changes in the remaining endogenous variables. All of the results are summarized in Table 2.

Theorem 1: $d r_{1}(x) / d t<0$ for all $x$.

Proof (by contradiction): Assume that $d r_{1}(x) / d t \geqq 0$ for all $x$. Therefore the gross price of housing services, $(1+t) p(x)$, increases. (Recall from Assumption 10 that the price of capital $s$ is fixed, so that the gross price of capital will rise by the full amount of the tax.) It follows from locational equilibrium (2.12) that the per capita demand for housing services must fall, because the level of utility and the level of public

${ }^{22}$ For three recent studies which complement the analysis in this section see Beckmann [3], Wile [22], and LeRoy [7]. 


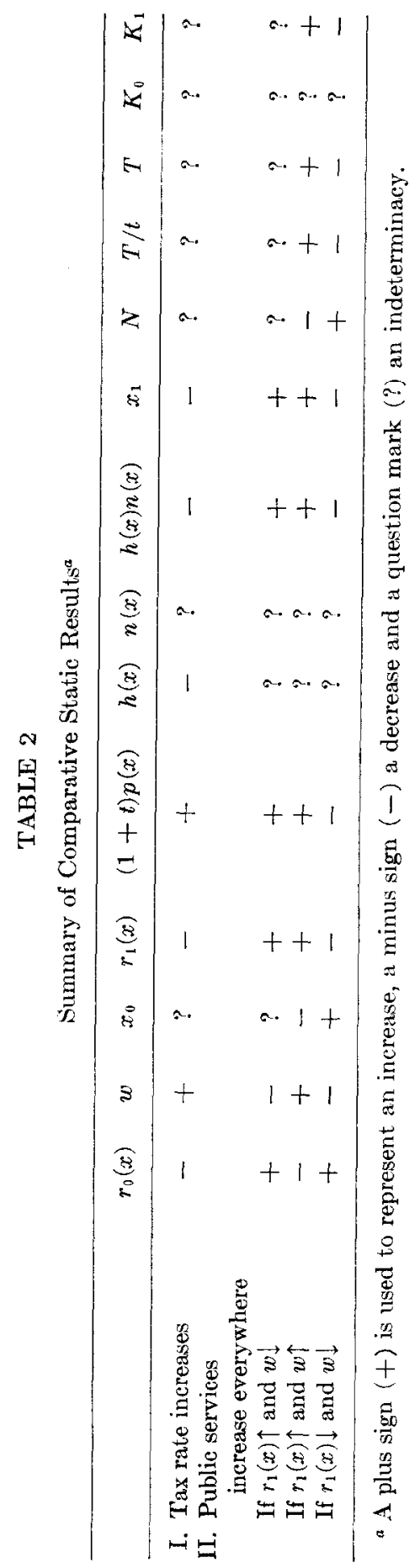


services are fixed, and the relative price of housing services has risen. In addition, (2.12) shows that the wage rate must rise; if this were not the case, the level of utility would be lower than in other cities. In the business sector, the consequence of a higher wage rate must be a decline in the business land price schedule, for if land prices did not fall, profits in the business sector would be negative (2.14). The fall in business land prices and the increase in residential land prices imply that the business-residential boundary $x_{0}$ contracts and the outer boundary $x_{1}$ expands. Since the producer of the private consumption commodity faces higher wages, lower land prices and a constant capital price, the demand for labor per unit of land at each location in the business district will fall (2.15). Given the decrease in the size of the business district, total population (labor demand) in the city must fall. To consider the effect of residential land price changes on population density, express land market equilibrium (2.13) as:

$$
n(x)=\frac{2 \pi x}{\left(-\frac{V_{1}(x)}{V_{2}(x)}\right) \frac{\partial \tilde{p}\left(r_{1}(x), w\right)}{\partial r_{1}(x)}} .
$$

Since residential land prices have not decreased (by assumption), the utilization of land per unit of housing services will fall or remain constant. Given that the per capita demand for housing services has fallen, population density will increase. Since the residential sector has increased in size ( $x_{0}$ has fallen and $x_{1}$ has increased), total population (labor supply) must rise. However, this contradicts the previous conclusion that population must fall. Therefore residential land prices must fall if equilibrium in the labor market is to be maintained. ${ }^{23}$

\section{Theorem 2: $d w / d t>0$.}

Proof (by contradiction): Assume that $d w / d t \leqq 0$. It follows that the gross price of housing falls (or remains constant if $d w / d t=0$ ) (2.12), and that housing demand per capita increases (or remains constant). Since wages fall (or remain constant), (2.14) shows that business land prices increase (or remain constant). Given the decline in residential land prices (Theorem 1), this guarantees that $x_{0}$ increases and $x_{1}$ falls. From (2.15) it follows that the demand for labor per unit

${ }^{23}$ To be complete it is necessary to consider the possibility that $r_{1}(x)$ falls at some locations and rises at others. From (2.12) it can be shown that the sign of $d r_{1}(x) / d t$ is the same as the sign of $\left[d w / d t-p(x)\left(-V_{1}(x) / V_{2}(x)\right)\right]$. Since $p(x)\left(-V_{1}(x) / V_{2}(x)\right)$, housing expenditures, is positive, the wage rate must rise if residential land prices rise at some locations. Only in what appears to be an unusual case, if the wage increase is greater than total housing expenditures, will land prices rise. 
of land will rise (or remain constant) and the total population (demand for labor) must increase. However, the increase in land per unit of housing services and the increased (or constant) demand for housing per capita imply that population density decreases (3.1). Since the residential sector has decreased in spatial size, the total population (supply of labor) must decrease. This contradiction shows that the wage must rise if equilibrium in the labor market is to be maintained. ${ }^{24}$

In the remainder of this section, we will discuss some additional issues relating to the effects of an increase in the residential property tax. If the wage rate were arbitrarily fixed in (2.12), it is not difficult to show that land prices would fall more (percentagewise) than the tax rate would rise and that the gross price of housing would remain unchanged. However, the wage rate increase (Theorem 2) moderates the magnitude of the decline in residential land prices. ${ }^{25}$ From locational equilibrium (2.12), with $b(x)$ fixed and $w$ increasing, the gross price of housing must rise if the level of utility is to remain unchanged. Thus, the property tax may be viewed in part as an excise tax on the consumption of housing services. (Of course, the net-of-tax price of housing will fall as a result of the decline in land prices.) At each location in the residential area consumers will purchase less housing and more of the private consumption commodity.

It is important to realize that the payment of higher wages associated with the property tax increase does not represent an increase in real purchasing power. Since the city is open and small (Assumptions 9 and 10), individuals will migrate to or from the city until utility is again equalized at the original level. It would be perfectly consistent for two cities in a system of cities to have different wage rates (paid in the same numeraire) for equal quality inputs of labor and yet for

${ }^{24}$ The wage increase results from the effects on the labor market of the residential property tax. If our analysis included an explicit tax on land and capital in the business sector, the wage change would become indeterminate since the initial response of the business sector would be to utilize additional laborers per unit of output thus lowering the marginal produet of labor, ceteris paribus.

${ }^{25}$ From (2.12) we may calculate the elasticity of residential land prices with respect to a change in the ad valorem tax rate. Using the implicit function theorem, we get

$$
\begin{aligned}
e_{r_{1}}(x)(1+t)=\frac{d r_{1}(x)}{d(1+t)} \cdot \frac{(1+t)}{r_{1}(x)} \\
=-\frac{p(x)}{r_{1}(x)\left(\partial p(x) / \partial r_{1}(x)\right)}+\frac{d w / d(1+t)}{\left(-V_{1}(x) / V_{2}(x)\right)\left(\partial p(x) / \partial r_{1}(x)\right)} .
\end{aligned}
$$

If the wage is fixed $(d w / d(1+t)=0)$ it follows that $e_{r_{1}}(x)(1+t)<-1$ (using the linear homogencity of the housing cost function (2.8)). Since the second term is positive, land prices will fall less when the wage is allowed to vary. 
both cities to be equally desirable as choices for residential location.." This suggests that tax capitalization studies which focus on long-run land price adjustments and which do not consider tax-induced wage rate changes may obtain misleading or incomplete results.

To examine the effects of the property tax change on population density, reconsider equation (3.1). The decline in residential land prices and the rise in the gross price of capital will lead to an increase in the amount of land used per unit of housing services (2.9). We have already argued that the amount of housing services demanded per capita will fall. Therefore, the changes in the demand for land per capita and population density will be indeterminate. Other things equal, the less price elastic the demand for housing and the higher the elasticity of substitution between land and capital, the more likely that population density will decrease when the tax rate is raised. While we cannot determine the direction of the change in population density, we can see from equation (3.1) that housing density (the amount of housing services consumed per unit of land),

$$
\left(-\frac{V_{1}(x)}{V_{2}(x)}\right) n(x)=\frac{2 \pi x}{\frac{\partial \tilde{p}\left(r_{1}(x), s\right)}{\partial r_{1}(x)}},
$$

must decrease solely because of the substitution of land for capital in the production of housing services.

Now consider the boundary conditions of the model. Since land prices have fallen everywhere within the residential sector, the outer boundary of the city will contract. ${ }^{27}$ The decline in city size is reasonable to expect, given the shift from city land use to rural land use associated with the residential property tax. ${ }^{28}$ Since the wage rate has risen, it is apparent from product market equilibrium (2.14) that land prices in the business sector must decline. The extent of the decline will depend on the substitutability of factors in the production of the

${ }_{26}$ This point does not appear to be realized generally. For example, Mieszkowski $[9$, p. 77] argues that "Capital and workers are perfectly mobile between communities so that after-tax rates of return on capital and wage rates are equal in all communities." The perfect mobility of labor implies that utility will be equalized, but it does not imply that money wage rates will be equalized. (We do not take issue with the statement relating to the return on capital.)

${ }^{27}$ Recall that we have assumed a downward sloping land price gradient in the neighborhood of the boundary areas. See footnotes 20 and 21 .

${ }^{28}$ It would be fallacious to conclude, however, that the city boundary would remain unchanged if agricultural land were taxed at the same rate as urban land, since with wage adjustments urban land prices may fall more or less than the percentage change in the tax. See footnote 25 . 
composite commodity. With the decline in business and residential land prices, the business-residential boundary change will be indeterminate.

We may complete our discussion of the business sector by examining labor market equilibrium (2.15). Since the wage rate has risen while business land prices have fallen, the demand for labor per unit of land will fall everywhere in the business district. If the CBD were to contract or remain constant in area, we could conclude that total population in the city must decline. However, the business sector could increase in area sufficiently to overcome the lower labor demand, leading to an increase in total population of the city. ${ }^{29}$ Thus, we cannot conclude that an increase in the residential property tax will lcad to an outmigration of the local population even when public services do not improve.

We now consider the three accounting identities in the model: total $\operatorname{tax}$ revenue (2.19), total residential capital (2.21), and total business capital (2.20), respectively. From our previous discussion we know that housing density (3.2) unambiguously declines. Since the net price of housing services has also fallen, we can conclude that the total value of taxable property falls at every point in the residential sector. If the residential sector falls in size, then the total tax base declines. However, the indeterminacy in the movement of the business-residential boundary makes this ambiguous. In any case, with an increase in the tax rate it is clear that the change in tax revenue is indeterminate.

The change in total residential capital can be analyzed similarly to the change in total tax revenues. We know that housing density (3.2) must decline. In addition, the utilization of capital per unit of housing services (2.10) will diminish with the fall in residential land prices. Thus, at every point in the residential sector, total capital used in the production of housing services will decrease. Total capital in the residential sector will decline unambiguously except in the special case when the business sector becomes sufficiently small, and the residential sector sufficiently large, to counteract the fall in capital used per unit of land.

Next consider whether total business capital will increase or decrease. The lower land price in the business sector and the higher wage will ensure that the demand for land per unit of output (2.5) will increase.

${ }^{29}$ Such a result might come about if the property tax rate increase led to a substantial decline in residential land prices and a very slight increase in the wage rate. For some production functions, a slightly higher wage would imply a slight decline in business land prices. The result is a substantial increase in the size of the business district. Since the wage rate and price of business land adjust only slightly, the demand for labor per unit of land falls very little. The net effect of the slightly diminished demand for labor per unit of land and the greatly increased size of the business sector would be an increase in total population. 
However, the change in capital demand per unit, of output will be indeterminate. Therefore the change in capital per unit of land is indeterminate, as is the change in total business capital.

\section{THE EFFECTS OF LOCAL PUBLIC SERVICES}

In this section we analyze the effects of an exogenous increase in public services holding the tax rate fixed. (The results are summarized in Table 2.) To accomplish this, we alter the model slightly so that public services depend on a shift parameter which we can vary exogenously. Formally we assume:

$$
b(x)=\tilde{b}(x, \lambda) \text { where } \frac{\partial \tilde{b}}{\partial \lambda}>0 \text { for all } x .
$$

It will be instructive to begin by considering two limiting cases in which first the wage rate and then residential land prices are held constant. ${ }^{30}$ With the wage rate fixed, if public services rise, the price of land must rise (2.12). Otherwise, the individual would achieve a level of utility exceeding $V^{*} .{ }^{31}$ With the price of land at each location fixed, it follows from locational equilibrium (2.12) that the wage will fall in response to public service improvements. If the wage did not fall, the individual's utility would exceed $V^{*}$.

These two limiting cases suggest that when both the wage rate and the price of land are allowed to vary, a mixture of the above effectssome rise in land prices and some fall in the wage rate--would occur. The magnitudes of these changes depend upon such things as the "complementarity" or "substitutability" between public services and housing, ${ }^{32}$ and the degree of factor substitutability in the production functions for housing and the private consumption commodity. We have not been able to produce a simple analytical example which illus-

${ }^{30}$ These cases cannot be treated simply as special cases of our model because they would necessitate the elimination of at least one market clearing condition. However, in an amended version of our model which imposed either a fixed wage rate or fixed residential land prices, the locational equilibrium condition (2.12) would still hold. This condition will be the only one used to illustrate the effects of public service improvements in the two limiting cases.

${ }^{31}$ In a model in which the wage rate is held fixed and the business sector is essentially ignored, Polinsky and Shavell [14] found that land prices unambiguously rise in an open city, but may fall in a closed city.

32 "Complementarity" and "substitutability" are used here to refer to the effects of public services on housing demand, ceteris paribus. For example, an improvement in air quality may increase the demand for back yards because back yards are more pleasant when the air is clem, although an improvement in public parks may decrease the demand for back yards. 
trates these results. To determine their plausibility it would be necessary to simulate the model using "reasonable" functional forms and parameter values.

Assuming that residential land prices rise and the wage rate falls, we can trace through the other effects on the city's equilibrium. Since the price of residential land rises, housing density rises (3.2) and the city-rural boundary will shift outward. The fall in the wage implies that the price of land in the business sector rises (2.14). Together with the rise in residential land prices, this implies that the business-residential boundary may move in either direction. This indeterminancy accounts for the indeterminancy of the remaining variables. In the business sector, labor per unit of land rises at each point because the wage falls and the price of land rises (2.15). The total demand for labor, and therefore the total population, will rise if the business sector expands in size, but may fall if it shrinks sufficiently. Likewise, the change in total tax revenue (2.19) is indeterminate even though tax revenue rises at each location in the residential sector (since housing density (3.2) and the net price of housing have both increased). Total tax revenue will rise if the business-residential boundary falls, but may fall if the boundary increases sufficiently. The change in total business capital (2.20) is indeterminate due to the indeterminancy of changes in both the boundary and the eapital-land ratio. In the residential sector, housing density and the capital intensity of housing production have gone up. Thus total residential capital (2.21) will rise if the business-residential boundary falls, but may fall if the boundary increases sufficiently.

When the wage rate and the price of residential land are allowed to adjust, outcomes other than a decrease in the wage and an increase in the price of land may occur. ${ }^{33}$ Although we have not been able to determine the specific conditions under which other possibilities occur, some intuitive explanations and examples can be provided. Since nothing has been assumed about the form of the utility function, the increase in public services may or may not be highly valued. Other things equal, the more public services are valued, the greater the adjustment in housing and private good consumption needed to equalize utility. In addition, an increase in public services may make housing consumption more or less desirable, everything else equal. When housing consumption falls in response to an increase in public services and public services are highly valued, the derived remand for land will

${ }^{33}$ Of the four possible combinations of changes in residential Iand prices and the wage, only the case in which the price of land falls and the wage rises is immediately ruled out by (2.12) since this combination implies a higher than equilibrium level of utility. 
fall substantially. 'This suggests lower residential land prices, a higher population and a lower wage.

The following example illustrates that both the price of land and the wage can fall as a result of public service improvements. Consider the "usual" result that a substantial increase in public services at each residential location leads to a decline in the wage rate and an increase in land prices everywhere. Now suppose that the improvement in public services is substantial at all locations in the residential sector but one, $x^{*},\left(\partial b\left(x^{*}\right) / \partial \lambda \simeq 0\right)$. Consider the locational equilibrium condition (2.12) at $x^{*}$. Since $w$ has fallen (any change at the single point $x^{*}$ could not possibly have an effect on the overall labor market equilibrium) and $b\left(x^{*}\right)$ has stayed essentially constant, the price of residential land at $x^{*}$ must fall to equalize utility at $V^{*} .^{34}$ Thus, even though public services improve everywhere, it is possible that the wage rate will fall and land prices will fall at some locations in the residential sector.

While this example establishes that the price of land might fall at some locations along with the wage rate, there is no apparent reason why residential land prices could not fall everywhere. However, this possibility can arise only when public services are highly valued and when an increase in public services greatly reduces the demand for residential housing. Assuming this to be the case, we can derive the implications for the structure of the city in its new equilibrium. Housing density (3.2) declines and the city-rural boundary shifts inward. The price of land in the business sector rises because the wage rate is lower (2.14), implying that the business-residential boundary shifts outward. From the labor market equilibrium (2.15) it is easy to see that total population rises since labor per unit of land in production of the private good rises and the business sector has become larger. Note that the assumption of strong substitutability between public services and housing is necessary for the increased population to reside in equilibrium in a smaller residential area in which houses are produced more land intensively, and in which the price of housing has fallen relative to the numeraire. The decreased size of the residential sector, along with the decrease in housing density and the net price of housing, implies

${ }^{34}$ To see this formally, differentiate (2.12) totally with respect to $\lambda$ and solve to get:

$$
\frac{d r_{1}(x)}{d \lambda}=-\frac{V_{2}(x) \frac{d w}{d \lambda}+V_{3}(x) \frac{\partial b(x)}{\partial \lambda}}{V_{1}(x)(1+t) \frac{\partial \tilde{p}}{\partial r_{\downarrow}}} .
$$

At point $x^{*}, \partial b\left(x^{*}\right) / \partial \lambda \simeq 0$ implies that the sign of $d r_{1}\left(x^{*}\right) / d \lambda$ equals the sign of $d w / d \lambda$. Since the wage rate is assumed to have fallen, it follows that $r_{1}\left(x^{*}\right)$ must also fall. 
that the tax base (and therofore tax revenue) diminishes (2.19). Even though the business sector is larger, the total utilization of business capital (2.20) may grow or decline depending on the nature of the private good production function. On the other hand, total residential capital (2.21) unambiguously falls since housing density, the capitaloutput ratio in housing and the size of the residential sector all decline.

The final possibility is for both the wage rate and the residential price of land to rise in response to a general improvement in public: services. Intuitively we would expect this result when housing services are very complementary with public services and public services themselves are not highly valued. A small increase in public services will then greatly increase the demand for housing and the derived demand for land, implying higher land prices, a lower population and a higher wage. To illustrate how this case might occur, consider an individual who lives at the outer edge of the city both before and after a general improvement in public services. Regardless of how the public service schedule changes, he will be paying the same price for land (the rural price of land $r_{2}$ ). Suppose that Iand prices rise everywhere and that at the new boundary $x_{1}{ }^{*}$ (which exceeds $x_{1}$ ) the level of public services after improvement, $b^{*}\left(x_{1}^{*}\right)$, just happens to be the same as the level of public services at the old boundary before the improvement, i.e. $b\left(x_{1}\right)=b^{*}\left(x_{1}^{*}\right) \cdot{ }^{35}$ Since the price of land (and therefore housing) and the level of public services are the same as before, and since journeyto-work costs are higher at the new boundary, the wage rate must rise to bring the individual's utility level up to $V^{*}(2.12)$. When residential land prices and the wage rate rise, all of the determinate changes in the city's equilibrium are just the opposite of the case in which land prices fall and the wage falls, and all of the indeterninate results remain.

The results of this section show that allowing both land prices and the wage rate to vary leaves the impact of public services in doubt. This is in contrast to the conventional view that public service increases will be capitalized as higher land prices, particularly in an open city. It also questions the view that wages would fall as a result of the increased attractiveness of the city.

\section{CONCLUDING REMARKS}

The natural next step in our analysis would be to derive the effects when the revenue raised by an increase in the property tax rate is used to finance spatially distributed public expenditures in a manner which balances the budget. To close the model in this way it would

${ }^{35}$ The equality is used only for simplicity. It is sufficient if $b^{*}\left(x^{*}{ }_{1}\right) \leq b\left(x_{1}\right)$ 
be necessary to specify a production function for aggregate local public services and a rule for distributing these services over space. While such a model can easily be specified, we have been unable to derive any formal results in the closed general equilibrium case. The possibility of feedback effects between tax revenue and expenditures greatly complicates the analysis.

Some intuitive understanding of the balunced-budget effects can be obtained by a comparison of the tax and public service results in Table 2. From the analysis of the tax side (holding public services fixed), we have learned that land prices will fall and that the wage will rise. From the analysis of the expenditure side (holding the tax rate constant), we have learned that changes in both land prices and the wage are indeterminate without further restrictions. Given this indeterminacy, it seems plausible that an analysis which combined the two sides and balanced the budget would also give indeterminate results. This suggests that the effects of the residential property tax in a balanced-budget analysis may be very different from those in the conventional analysis (including our own) which holds public services constant.

\section{REFERENCES}

1. H. J. Aaron, "Who Pays the Property Tax? A New View," Brookings, Washington (1975).

2. J. L. Barr, City Size, Land Rent, and the Supply of Public Goods, Regional and Urban Economics, 2, 67-103 (1972).

3. M. J. Beckmann, Spatial Equilibrium in the Housing Market, Journal of Urban Economics, 1, 99-107 (1974).

4. P. N. Courant and D. L. Rubinfeld, On the Measurement of Benefits in an Urban Context: Some General Equilibrium Issues, Journal of Urban Economics, to appear.

5. R. E. Grieson, The Economics of Property Taxes and Land Values: The Elasticity of Supply of Structures, Journal of Urban Economics, 1, 367-381 (1974).

6. J. F. Kain and J. M. Quigley, Measuring the Value of Housing Quality, Journal of the American Statistical Association, 65, 532-548 (1970).

7. S. F. LeRoy, Urban Land Rent and the Incidence of Property Taxes, Journal of Urban Economics, 3, 167-179 (1976).

8. R. C. Lind, Spatial Equilibrium, the Theory of Rents, and the Measurement of Benefits from Public Programs, Quarterly Journal of Economics, 87, 188-207 (1973).

9. P. Mieszkowski, The Property Tax: An Excise Tax or a Profits Tax?, Journal of Public Economics, 1, 73-96 (1972).

10. D. Netzer, "The Economics of the Property Tax," Brookings, Washington (1966).

11. W. D. Nordhaus and J. Tobin, "Economic Growth," National Bureau of Economic Research, New York (1972).

12. W. E. Oates, The Effects of Property Taxes and Local Public Spending on Property Values: An Empirical Study of Tax Capitalization and the Tiebout Hypothesis, Journal of Political Economy, 77, 957-971 (1969). 
13. L. L. Orr, The Incidence of Differential Property Taxes on Urban Housing, National Tax Journal, 21, 253-262 (1968).

14. A. M. Polinsky and S. Shavell, Amenities and Property Values in a Model of an Urban Area, Journal of Public Economics, 5, 119-129 (1976).

15. R. G. Ridker and J. A. Henning, The Determinants of Residential Property Values with Special Reference to Air Pollution, Review of Economics and Statistics, 49, 246-256 (1967).

16. E. R. Rolph and G. Break, "Public Finance," Ronald Press, New York (1961).

17. C. Shoup, "Public Finance," Aldine, Chicago (1969).

18. H. A. Simon, The Incidence of a Tax on Urban Real Property, Quarterly Journal of Economics, 57, 398-420 (1943).

19. R. M. Solow, On Equilibrium Models of Urban Location, in "Essays in Modern Economics" (M. Parkin, Ed.), Longman, London (1973).

20. R. H. Strotz, The Use of Land Rent Changes to Measure the Welfare Benefits of Land Improvement, in "The New Economics of Regulated Industries: Rate Making in a Dynamic Fconomy" (J. F. Haring, Ed.), Occidental College, Los Angeles (1968).

21. G. S. Tolley, The Welfare Economies of City Bigness, Journal of Urban Economics, 1, 324-345 (1974).

22. J. H. Wile, The Inpacts on Welfare and Urban Structure of Conversion Fron the Property to the Income Tax, unpublished manuscript, Department of Economics, State University of New York at Stony Brook (1975). 